\title{
Differences in the Level of Social Status of Male and Female Folk Dancers
}

\author{
Evagelia Bolia, Dragan Popovića ${ }^{a}$, Biljana Karanovb, Milica Bojevića, Marina Jovanovića
}

\begin{abstract}
The research was conducted in order to determine differences in the social status structure of male and female performers of folk dances. For the purpose of determining the social status structure of male and female dancers, 103 male and 145 female dancers aged 18-28 actively engaged in folk dancing were tested. For the assessment of social status, only one model that allows for true scientific approach to studying the structure of stratification dimensions has been made so far. The model was constructed by Saksida and later served as a basis for many studies conducted by other authors as well (Saksida, Caserman, Petrovic, Momirovic, and Hosek). Designed as a phenomenological model, it has undergone several changes over time, but it is still suitable for studying social change. The INST2 questionnaire modified by Boli, Popovic, Hosek, Momirovic, and Savic (SSMIN) was applied in this study. All the data obtained in this research were processed at the Multidisciplinary Research Center of the Faculty of Sport and Physical Education, University of Pristina, through the system of data processing programs designed by D. Popovic and K. Momirovic. To determine differences between the groups, a method of discriminant analysis was applied.
\end{abstract}

\section{Keywords}

Structure, discriminant, social status, correlation

The intelligent and socialized behaviors are, from both an individual and social point of view, two most important modalities of human behavior. However, while psychologists have developed thousands of reliable and valid tests of the efficiency of cognitive functions, the number of measurement instruments on the basis of which it could be estimated in a fairly reliable and relevant way whether someone in the family, at school or work behave in a socially adjusted, that is, mature, polite, and civilized manner is lower than the number of measurement instruments for the assessment of any relevant psychic function.

There are several reasons that are responsible for this unhealthy condition. The first reason is, of course, the position of the socialization construct in the space of conative functions. This construct does not exist in any serious, that is, mathematical theory of personality, except for the cybernetic theories of conative functions in which the degree of socialized behavior is considered to be a manifestation of the functioning of the evaluation system, and this construct is hardly mentioned or is not mentioned at all even in the best and most comprehensive psychology dictionaries. The second reason is the orientation of psychologists and

\footnotetext{
aUniversity of Pristina, Serbia

bSports Academy, Belgrade

\section{Correspondent Author:}

Dragan Popović, Kosanciceva 17, Krusevac, Serbia, Zip code 37000

E-mail: dragan.popovic@pr.ac.rs
} 
parapsychologists who have dealt with this area. Partly because of the effects of schizophrenic onomatopoeia caused by the first syllable of the word, socialization construct is left to those whom the late Professor Ramiro Bujas would call "philosophic" sort of psychologists, who neither want nor are they able to measure and calculate. This has led to the fact that when making attempts to assess the degrees of socialization in an objective way, they applied methods of dubious reliability and still worse validity whose authors themselves could not define the subject of their measurement. The third reason is the implicit relocation of the factors, on which socialized behavior depends, from the space of conative factors, i.e., from the space of personality traits that have a clear and distinct physiological basis. However, no reasonable person would deny that exogenous, primarily social factors have a significant and sometimes substantial influence on the formation of conative characteristics, explicit acceptance of the fact that socialized behavior depends on the same neural structures on which any other behavior depends was totally unacceptable not only for the so-called humanistically oriented psychologists, but also for the so-called humanistic intellectuals in general who, largely due to the inertial effects of ideological and religious scotomas, considered this evident fact as biological reductionism and were reluctant to support the efforts to tackle the issue of socialized behavior using means and methods of experimental and mathematical psychology.

This study is a continuation but not the end of the longstanding efforts of all the authors to start solving the problem of socialized behavior in a useful way. The first step in this endeavor was to develop standardized measurement instruments to assess socialized behavior in an objective, reliable, and valid way so as to recognize direct factors of such behavior, the relationship of these factors with other personality traits, and the relationship between these factors and real human behavior in different life circumstances and environments.
And the authors, as well as all those who supported and ensured studies necessary for the construction of psychological measurement instruments, were quite aware that it was not an easy task. Being complex and poorly researched, the area of socialization required application of the methods which were not necessary though could be useful in the construction of measurement instruments to assess other psychic characteristics.

Besides that, as the assessment of the factors on which socialized behavior depends is not a neutral operation from both an individual and social point of view, the authors felt it necessary to explicitly specify what means they had used, thus enabling everyone to check the results and possibly continue their research. This has led to the fact that reading some parts of the study will be difficult for some psychologists, whose education in statistics, psychometrics, and IT (Information Technology) is average or outdated. However, judging by the plans, programs, and qualifications of teachers of statistics and psychometrics at serious faculties in Serbia, the knowledge acquired by students in the first two years of university for the last decade would be sufficient for understanding most of the paper.

To make this study moderately extensive and easy-to-read, the authors, working on its latest edition, have decided to retain only those parts of the paper which they consider absolutely necessary and remove a substantial portion of the paper referring to the application of alternative, primarily nonlinear models for data analysis in solving problems of factorial and pragmatic validity as well as a considerable number of additional explicative analyses designed for better identification of the factors on which the level of socialized behavior depends. Since the authors are not quite sure whether they have taken a good decision, they will strive, together with their associates, to publish some of those papers in journals or other publications with a regular review procedure. 


\section{METHODS}

\section{Sample of Respondents}

The population from which the sample was drawn for this study can be defined as a population of male and female folk dancers from folk dance ensembles of Serbia aged 18-28. Based on the posed problem, reseach subject and objective, and taking into account organizational and financial capabilities necessary for this study, an optimal number of respondents were taken into the sample in order to perform the research correctly and obtain exact results. The sample of respondents consisted of 248 male and female folk dancers, members of folk dance ensembles of Serbia, which was the optimal number for the planned study.

The respondents met the following criteria: The age was defined on the basis of chronological age, so respondents aged 18-28 were covered by the study, they had neither organic nor somatic diseases and were active members of folk dance ensembles. The research was conducted in the folk dance ensembles as follows: "Vuk. St. Karadzic" from Backa Topola, "Svetozar Markovic" from Novi Sad, "Zeleznicar", "Vila" from Novi Sad, "Ravangrad" from Sombor, "Kosta Abrasevic" from Backa Palanka, "Stepino Kolo" from Stepanovicevo, "Taras Shevchenko" from Djurdjevo, "Kisac" from Kisac, "Sonja Marinkovic" from Novi Sad, "Soko" from Indjija.

\section{Sample of Variables of Musicality}

For the social status assessment, only one model that provides a true scientific approach to studying the structure of stratification dimensions has been developed so far. The model was constructed by Saksida and later served as a basis for many studies conducted by other authors as well (Saksida, Caserman, Petrovic, Momirovic, and Hosek). Designed as a phenomenological model, it has undergone several changes over time, but it still remains suitable for studying social change. INST2 and SSMIN questionnaire modified by Boli, D.
Popovic, Hosek-Momirovic, J. Popovic, and Savic (2012) were applied in this study.

\section{Data Processing Methods}

There is not a single researcher nowadays who has not applied at least once a model of multivariate analysis without understanding its logic during his life career. That is why the problem of selecting a particular method of data processing is rather complex. Therefore, the value of a research depends not only on the sample of respondents or the values of basic information, but also on the applied methods for transformation and condensation of the information. Certain scientific problems can be solved with the help of a big number of different, and sometimes equally valuable methods. However, with the same basic data, different conclusions can be drawn from the results of different methods.

In order to come to satisfactory scientific conclusions, the researchers applied primarily correct and then adequate, impartial, and comparable methods that conformed to the nature of the stated problem and made it possible to determine differences between the groups and established regularities within the research area.

Taking this into account, for the purposes of this study, the researchers selected those methods that correspond to the nature of the problem and did not leave too heavy restrictions on the basic information. To determine differences between the groups, a method of discriminant analysis was applied.

All data obtained in this study were processed at the Multidisciplinary Research Center of the Faculty of Sport and Physical Education, University of Pristina, through the system of data processing programs developed by Popovic (1980; 1993a; 1993b) and Momirović and Popovic (2003).

Canonical discriminant analysis. Canonical discriminant analysis can now be defined as the solution of the quasi canonical problem $\mathrm{Mx}_{\mathrm{k}}=\mathrm{k}_{\mathrm{k}}, \mathrm{Gy}_{\mathrm{k}}$ $=\mathrm{l}_{\mathrm{k}} \mid \mathrm{c}_{\mathrm{k}}=\mathrm{k}_{\mathrm{k}}{ }^{\mathrm{t}} \mathrm{l}_{\mathrm{k}}=$ maximum, $\mathrm{x}_{\mathrm{k}}{ }^{\mathrm{t}} \mathrm{x}_{\mathrm{q}}=\mathrm{y}_{\mathrm{k}}{ }^{\mathrm{t}} \mathrm{y}_{\mathrm{q}}=\delta_{\mathrm{kq}} \mathrm{k}=1, \ldots$, 
$\mathrm{s} ; \mathrm{s}=\min [(\mathrm{g}-1), \mathrm{m}]=\mathrm{m}$ where $\delta_{\mathrm{kq}}$ is Kronecker symbol and $\mathrm{x}_{\mathrm{k}}$ and $\mathrm{y}_{\mathrm{k}}$ are unknown m-dimensional vectors.

As $c_{k}=x_{k}{ }^{t} A y_{k}$, the function to be maximized is, for $\mathrm{k}=1, f\left(\mathrm{x}_{\mathrm{k}}, \mathrm{y}_{\mathrm{k}}, \lambda_{\mathrm{k}}, \eta_{\mathrm{k}}\right)=\mathrm{x}_{\mathrm{k}}{ }^{\mathrm{t}} \mathrm{A} \mathrm{y}_{\mathrm{k}}-2^{-1} \lambda_{\mathrm{k}}\left(\mathrm{x}_{\mathrm{k}}{ }^{\mathrm{t}} \mathrm{x}_{\mathrm{k}}-1\right)-$ $2^{-1} \eta_{k}\left(y_{k}{ }^{t} y_{k}-1\right)$.

After differentiating this function by elements of vectors $\mathrm{x}_{\mathrm{k}}, \partial f / \partial \mathrm{x}_{\mathrm{k}}=A \mathrm{y}_{\mathrm{k}}-\lambda_{\mathrm{k}} \mathrm{x}_{\mathrm{k}}$, and differentiating it by elements of vectors $y_{k}, \partial f / \partial y_{k}=A x_{k}-\eta_{k} y_{k}$; after equalizing with zero, $A y_{k}=\lambda_{k} x_{k}$ and $A x_{k}=\eta_{k} y_{k}$. Through differentiating by $\lambda_{\mathrm{k}}$ and $\eta_{\mathrm{k}}$, from the condition that $\mathrm{x}_{\mathrm{k}}{ }^{\mathrm{t}} \mathrm{x}_{\mathrm{k}}=1$ and $\mathrm{y}_{\mathrm{k}}{ }^{\mathrm{t}} \mathrm{y}_{\mathrm{k}}=1$, it is easily obtained that $\lambda_{k}=\eta_{k}$. As $A^{t}=A$, multiplying the first result by $\mathbf{x}_{\mathrm{k}}{ }^{\mathrm{t}}$ and the second result by $\mathrm{y}_{\mathrm{k}}{ }^{\mathrm{t}}, \mathrm{x}_{\mathrm{k}}{ }^{\mathrm{t}} \mathrm{Ay_{ \textrm {k } }}=\mathrm{k}$ and $\mathrm{y}_{\mathrm{k}}{ }^{\mathrm{t}} \mathrm{Ax} \mathrm{x}_{\mathrm{k}}=\mathrm{k}_{\mathrm{k}} \mathrm{x}_{\mathrm{k}}=\mathrm{y}_{\mathrm{k}}$, therefore, $\mathrm{x}_{\mathrm{k}}=\mathrm{y}_{\mathrm{k}}$, and the problem comes down to an ordinary problem of eigenvalues and eigenvectors of matrix $\mathrm{A}$, that is, the solution of the problem $\left(\mathrm{A}-\lambda_{\mathrm{k}} \mathrm{I}\right) \mathrm{x}_{\mathrm{k}}=0, \mathrm{k}=1, \ldots \mathrm{m}$, so $c_{k}=\rho_{k}{ }^{2}=x_{k}{ }^{t} A x_{k}=\rho_{k}, k=1, \ldots m$ are squares of canonical correlations between the linear combinations of variables from $\mathrm{M}$ and $\mathrm{G}$ which are proportional to the differentiation of centroids of the subsamples defined by selector matrix $\mathrm{S}$ in the space spanned by the vectors of variables from $\mathrm{M}$.

Let $\rho^{2}=\left(\rho_{\mathrm{k}}^{2}\right), \mathrm{k}=1, \ldots \mathrm{m}$ be a diagonal matrix whose elements are squares of canonical correlations, let $\mathrm{X}=\left(\mathbf{x}_{\mathrm{k}}\right), \mathrm{k}=1, \ldots \mathrm{m}$ be a matrix of the eigenvectors obtained by solving the canonical discriminant problem, let $\mathrm{K}=\mathrm{MX}$ be a matrix of discriminant functions and let $\mathrm{L}=\mathrm{GX}=\mathrm{PMX}$ be a matrix of the discriminant functions projected in the hypercube defined by vectors of matrix $\mathrm{S}$. As $\mathrm{K}^{\mathrm{t}} \mathrm{L}=$ $\mathrm{X}^{\mathrm{t}} \mathrm{AX}=\rho^{2}$ and as, of course, $\mathrm{K}^{\mathrm{t}} \mathrm{K}=\mathrm{I}$ and $\mathrm{L}^{\mathrm{t}} \mathrm{L}=\rho^{2}$, the canonical discriminant analysis produces two biorthogonal sets of vectors of variables by such transformation of the vectors of variables from $\mathrm{M}$ and $G$ that orthogonalizes those vectors and maximizes cosines of the angles between the corresponding vectors from $\mathrm{K}$ and $\mathrm{L}$, with the additional condition that the cosines of the angles of non-corresponding vectors from $\mathrm{K}$ and $\mathrm{L}$ are equal to zero because the correlations between the variables from $\mathrm{K}$ and $\mathrm{L}$ are $\mathrm{K}^{\mathrm{t}} \mathrm{L} \rho^{-1}=\mathrm{X}^{\mathrm{t}} \mathrm{AX} \rho^{-1}=\rho$.

Vectors $\mathrm{x}_{\mathrm{k}}$ from $\mathrm{X}$ are, obviously, the vectors of standardized partial regression coefficients of variables from $\mathrm{M}$ that generate discriminant functions $k_{k}$ which, together with discriminant functions $l_{k}$ formed by vectors of standardized partial regression coefficients $x_{k}$ from $G$ variables, have maximum correlations. But as $\mathrm{M}^{t} \mathrm{~K}=\mathrm{X}$, the elements of matrix $\mathrm{X}$ are, at the same time, the correlations of variables from $\mathrm{M}$ and discriminant variables from $\mathrm{K}$, which unlike the standard canonical discriminant model, allows easy testing of hypotheses about partial impact of variables on the formation of discriminant functions. For the identification of discriminant functions, the elements of the cross structural matrix defined as correlations between variables from $\mathrm{M}$ and $\mathrm{L}$, that is, the elements of matrix $\mathrm{Y}=\mathrm{M}^{\mathrm{t}} \mathrm{L} \rho^{-1}=\mathrm{AX} \rho^{-1}=\mathrm{X} \rho$, can also be of certain significance; note, by the way, that $\mathrm{Y}$ is a factor matrix of matrix A because, naturally, $Y Y^{t}=X \rho^{2} X^{t}$.

As elements $\mathrm{X}_{\mathrm{jk}}$ of matrix $\mathrm{X}$ and elements $\mathrm{y}_{\mathrm{jk}}$ of matrix $\mathrm{Y}$ are ordinary correlations, their asymptotic variances are $\sigma_{\mathrm{xjk}}^{2}=\left(1-\mathrm{x}_{\mathrm{jk}}^{2}\right)^{2} \mathrm{n}^{-1}$, respectively, $\sigma_{\mathrm{yjk}}{ }^{2}=$ $\left(1-\mathrm{y}_{\mathrm{jk}}{ }^{2}\right)^{2} \mathrm{n}^{-1}$, therefore, hypotheses of type $\mathrm{H}_{0 \mathrm{xjk}}$, or $\mathrm{H}_{0 \mathrm{yjk}}$, can be tested on the basis of the functions $\mathrm{f}_{\mathrm{xjk}}=$ $\mathrm{x}_{\mathrm{jk}}^{2}\left[(\mathrm{n}-2)\left(1-\mathrm{x}_{\mathrm{jk}}^{2}\right)\right]$, or $\mathrm{f}_{\mathrm{yjk}}=\mathrm{y}_{\mathrm{jk}}{ }^{2}\left[(\mathrm{n}-2)\left(1-\mathrm{y}_{\mathrm{jk}}{ }^{2}\right)\right]$, because under these hypotheses, the functions have the Fisher-Snedecor F-distribution with the degrees of freedom of $v_{1}=1$ and $v_{2}=n-2$.

Unfortunately, with a usual application of canonical discriminant analysis, the main, and often the only, set of hypotheses related to the parameters of that model is the set $\mathrm{H}_{0}=\left\{\varphi_{\mathrm{k}}=0, \mathrm{k}=1, \ldots \mathrm{m}\right\}$ where $\varphi_{\mathrm{k}}$ are hypothetical values of canonical correlations in population $\mathrm{P}$.

To test the hypotheses of type $\mathrm{H}_{0 \mathrm{k}}: \varphi_{\mathrm{k}}=0 \mathrm{k}=1, \ldots$ $\mathrm{m}$, researchers usually apply the function of the known Wilks measure $\lambda_{\mathrm{k}}=\Sigma_{\mathrm{t}+1} \mathrm{~s} \log _{\mathrm{e}}\left(1-\rho_{\mathrm{t}+1}^{2}\right) \mathrm{k}=\mathrm{t}+$ $1, \mathrm{t}=0,1, \ldots \mathrm{m}-1$ proposed by Bartlett (1941), who found that under the hypothesis $\mathrm{H}_{0 \mathrm{k}}: \varphi_{\mathrm{k}}=0$, the 
functions $\chi_{\mathrm{k}}{ }^{2}=-[\mathrm{n}-(\mathrm{m}+\mathrm{g}+3) / 2] \lambda_{\mathrm{k}} \mathrm{k}=1, \ldots \mathrm{m}$ have, approximately, $\chi^{2}$ distribution with the $v_{\mathrm{k}}=(\mathrm{m}-\mathrm{k}+$ 1) $(g-k)$ degree of freedom.

However, the results of Bartlett test are not, even when dealing large samples, in full accordance with the results of the tests of type $z_{k}=\rho_{k} / \sigma_{k} k=1, \ldots s$ which are based on the fact that canonical correlations have also asymptotic normal distributions with parameters $\varphi_{\mathrm{k}}$ and $\sigma_{\mathrm{k}}^{2} \sim\left(1-\varphi_{\mathrm{k}}^{2}\right)^{2} \mathrm{n}^{-1}$ (Kendall and Stuart 1968; Anderson 1984).

The centroids of the subsamples $E_{p}, p=1, \ldots g$ from $\mathrm{E}$ on discriminant functions necessary to identify the content of the discriminant functions are, of course, the elements of the matrix $\mathrm{C}=\left(\mathrm{S}^{\mathrm{t}} \mathrm{S}\right)^{-1} \mathrm{~S}^{\mathrm{t}} \mathrm{K}=$ $\left(\mathrm{S}^{\mathrm{t}} \mathrm{S}\right)^{-1} \mathrm{~S}^{\mathrm{t}} \mathrm{MX}=\left(\mathrm{S}^{\mathrm{t}} \mathrm{S}\right)^{-1} \mathrm{~S}^{\mathrm{t}} \mathrm{R}^{-1 / 2} \mathrm{X}$, and it is clear that they are, in fact, the centroids of the subsamples on the variables transformed into a Mahalanobis form projected into the discriminant space.

\section{DISCUSSION}

The results of the discriminant analysis in the space of social status are shown in Tables 1-4. By analyzing them, it is possible to determine that a significant canonical correlation of .34 was obtained. It explains $100.0 \%$ of the valid variance of the whole system of the evaluated space.

This discriminant function is defined by the achieved sport results (SPORTAC), type of school (SCHOOL), sport in which father was engaged (SPORTFA), size of living space (APARTM), household income (INCOME), type of place where the respondent lived as a child until 15 years of age (P15), type of place where father lived as a child until 15 years of age (P15FA), type of place where mother lived as a child until 15 years of age (P15MO), mother's professional qualification (QUALMO), education of maternal grandfather (MAGRFA), mother's knowledge of foreign languages (FOLMO).

It is important to note that the variables (SPORTFA and SPORT) refer to the names of sports in which the respondents, or their parents, were involved, and their numeration refers to the order and not the quantification. The biggest number (19) indicates that the respondent was not engaged in any sport, while the number which is one less (18) means "other sports" which are not among the responses offered, so the respondents differ in the selection of sports and it is not correct to interpret that male or female dancers are "better", they are just engaged in a different sport.

The variable (SPORTAC) that discriminates the two groups in favor of the male dancers can be interpreted from the standpoint that in Serbia, which is traditionally agrarian with prevalent patriarchal value system (although gender equality is proclaimed), women are less involved in sports. Therefore, a large number of women opt for dancing which is reflected in the structure of the sample of respondents where there are more female than male dancers, 103 male dancers and 145 female dancers from 10 folk dance ensembles participated in the research as respondents.

The variable (SCHOOL), quantifying the educational status of the individual in the socialization subsystem of social status, discriminates the two groups of respondents in favor of the male dancers. Most of the respondents live in small towns and villages. As Serbia is going through a transition period and is traditionally agrarian with prevalent patriarchal value system which is still more dominant in less developed rural areas, the proportion of uneducated women is significantly higher. According to the 2011 census, illiteracy as well as the lowest levels of education among women in Serbia are much higher than among men. There are 454 illiterate women per 100 illiterate men (Cikic 2014).

The variables (APARTM and INCOME), quantifying the basic economic status in the sanction subsystem of social status, discriminate the two groups of respondents in favor of the female dancers, i.e., it can be concluded that female dancers originate from wealthier families than male dancers. 
Table 1. Discriminant Analysis of Variables of Social Status

\begin{tabular}{lllllllll}
\hline Function & Eigenvalues & Variance (\%) & Cumulative (\%) & $\begin{array}{l}\text { Canonical } \\
\text { corelation }\end{array}$ & Wilks' lambda & Chi-skor & df & Sig. \\
\hline 1 & 15.80 & 100.0 & 100.0 & .97 & .060 & 4.232 & 3 & .00 \\
\hline
\end{tabular}

Table 2. Matrix M

\begin{tabular}{|c|c|c|}
\hline \multicolumn{2}{|l|}{ Variables } & \multirow{2}{*}{$\begin{array}{l}\text { Function } 1 \\
-.90\end{array}$} \\
\hline & SPORTACa & \\
\hline & SCHOOLa & -.90 \\
\hline & SPORTFA & -.80 \\
\hline & APARTMa & .72 \\
\hline & SPORTa & .50 \\
\hline & INCOMEa $^{a}$ & .46 \\
\hline & $\mathrm{P} 15^{\mathrm{a}}$ & .42 \\
\hline & P15FA & .42 \\
\hline & P15M0a & .42 \\
\hline & PLACEa & .42 \\
\hline & QUALMOa $^{a}$ & -.28 \\
\hline & EDUMAGRFA & .27 \\
\hline & FOLMOa & -.21 \\
\hline & EDUFA & -.12 \\
\hline & QUALFA $^{\mathrm{a}}$ & .12 \\
\hline & EDUPAGRFA $^{\mathrm{a}}$ & .11 \\
\hline & ACACHIEVa & -.11 \\
\hline & FOLFA & .04 \\
\hline & SPORTMOa & .03 \\
\hline & EDUMO & -.01 \\
\hline
\end{tabular}

Notes: a INST2-questionnaire for social status assessment, SSMIN-INST2 questionnaire modified by Boli, Popovic, Hosek, Momirovic, and Savic (2012). EDUMAGRFA-maternal grandfather's education; EDUFA-father's education; QUALFA—father's qualifications; EDUPAGRFA-paternal grandfather's education; ACACHIEV-respondent's academic achievement grades; FOLFA—father's foreign language knowledge; SPORTMO-kind of sport the respondent's mother is involved in; EDUMO-mother's education.

Table 3. Structure of Variables of Social Status

\begin{tabular}{|c|c|c|}
\hline \multicolumn{2}{|l|}{ Variables } & \multirow{2}{*}{$\begin{array}{l}\text { Function } 1 \\
-.90\end{array}$} \\
\hline & SPORTACa & \\
\hline & SCHOOLa & -.90 \\
\hline & SPORTFA & -.80 \\
\hline & APARTMa & .72 \\
\hline & SPORTa & .50 \\
\hline & INCOMEa $^{a}$ & .46 \\
\hline & $\mathrm{P} 15^{\mathrm{a}}$ & .42 \\
\hline & P15FA & .42 \\
\hline & $\mathrm{P} 5 \mathrm{MO}^{\mathrm{a}}$ & .42 \\
\hline
\end{tabular}


Table 3 continued

\begin{tabular}{|c|c|c|}
\hline \multicolumn{2}{|l|}{ Variables } & \multirow{2}{*}{$\begin{array}{l}\text { Function } 1 \\
.42\end{array}$} \\
\hline & PLACEa & \\
\hline & QUALMOa & -.28 \\
\hline & EDUMAGRFA & .27 \\
\hline & FOLMOa & -.21 \\
\hline & EDUFA & -.12 \\
\hline & QUALFAa & .12 \\
\hline & EDUPAGRFAa & .11 \\
\hline & ACACHIEVa & -.11 \\
\hline & FOLFA & .04 \\
\hline & SPORTMO & .03 \\
\hline & EDUMO & -.01 \\
\hline
\end{tabular}

Note: a INST2-questionnaire for social status assessment, SSMIN-INST2 questionnaire modified by Boli, Popovic, Hosek, Momirovic, and Savic (2012). EDUMAGRFA-maternal grandfather's education; EDUFA-father's education; QUALFA—father's qualifications; EDUPAGRFA-paternal grandfather's education; ACACHIEV—respondent's academic achievement grades; FOLFA—father's foreign language knowledge; SPORTMO-kind of sport the respondent's mother is involved in; EDUMO-mother's education.

Table 4. Centroids of the Groups

\begin{tabular}{ll}
\hline Group & Centroid 1 \\
\hline Female dancers & 3.77 \\
Male dancers & -2.51 \\
\hline
\end{tabular}

Characteristics of the places where the respondents as well as their parents spent their childhood (P15, P15FA, P15MO), quantifying the residential status of the socialization subsystem of social status, indicate that the female dancers spent their childhood in bigger places than the male dancers. The variable (PLACE), quantifying the residential status of the sanction system of social status and referring to the type of place of residence of the respondents (with their families), discriminates the two groups of respondents in favor of the female dancers.

Taking into consideration the fact that incomes of urban households are on average higher than incomes of rural households that there are differences in the educational structure which primarily refer to the more unfavorable structure of women and rural population, that Serbia's population enters the transition period with distinct gender inequalities in the educational structure (in 1981, there were 416 illiterate women per 100 illiterate men, compared with 454 illiterate women per 100 illiterate men in 2011, which is higher than in the pre-transition period, but there are more women in the highly educated population) and that involvement in any activity of all the spheres, including culture (folk art, folk dancing), implies financial investments (in Serbia, in its transition period, the ideological context as well as conditions leading to the process of commodification in culture-subordinating culture to the laws of the market and profitability have been taken from the most developed countries of Western Europe), it can be assumed that only wealthy families can provide equal investments in the cognitive development of all family members regardless of gender.

The variable assessing the institutionalization subsystem, including professional status which 
determines the degree of expert power of the individual, and referring to mother's recognized professional qualification (QUALMO), discriminates the two groups of respondents in favor of the male dancers. After the Second World War, the socialist government tried (and succeeded to some extent) to democratize the educational process in order to mitigate the existing social differences in the educational structure, and these differences were, first of all, related to the more unfavorable structure of women and rural population (Cikic 2014). The attitude about needlessness of education gets modified, gradually and often with difficulties (in undeveloped areas or in case of women education) (Cikic 2014) during the post-socialist transition period. The population of Serbia enters the transition period with extremely pronounced gender inequalities in the educational structure. Lower educational qualifications of women result in their lower economic activity, lower job positions, and therefore, social status (in 1981, 34.4\% of women and $59.9 \%$ of men were employed). It can be assumed that with the increase of awareness of the necessity of gender equality during the post-socialist transition period, women's influence becomes stronger in Serbia and the families, in which the women's qualifications are higher, have a higher social status, and therefore, higher influence on the education of family members which results in transferring affection for dancing, considered to have a reputation of women activity, to the male family members (sons).

The variable of maternal grandfather's education (MAGRFA), quantifying the educational status of the individual to assess the socialization subsystem of social status, discriminates the two groups of respondents in favor of the male dancers. According to Bucal (2012), a large number of studies indicate a positive correlation between the socioeconomic status and educational attainment. Based on the findings obtained in this research, female dancers have a better basic economic status and a better residential status, which may be a consequence of the traditionally (grandfather) higher educational attainment in the family.

The variable of mother's knowledge of foreign languages (FOLMO), quantifying the educational status to assess the socialization subsystem, as well as the variable (SCHOOL) which also quantifies the educational status, discriminates the two groups of respondents in favor of the male dancers.

Based on the values and signs of the centroids for the first discriminant function of the groups, it can be concluded that male dancers have a better educational status - the individual's level of education, mother's social status in the socialization subsystem, professional status expressed by mother's degree of expert power in her working organization, as well as greater achievement in sport. Female dancers have a better language-knowledge status and a better economic status quantified by the variables (APARTM) and (INCOME), as well as residential status quantified by the variable (PLACE) and basic residential status - characteristics of the place where the subject spent his or her childhood, and partially educational status (EDUMAGRFA). Comparing the discriminant analysis results to the regression analysis data shows that success in dancing is influenced by the variables (SCHOOL), where male dancers are better, APARTM and INCOME, where female dancers are better, and FOLMO, mother's knowledge of foreign languages, where male dancers are better.

\section{CONCLUSIONS}

The research was conducted in order to determine differences in the social status structure of male and female performers of folk dances.

To determine differences in the social status structure of male and female folk dance performers, 103 male and 145 female dancers aged 18-28 actively involved in folk dancing were tested.

For the social status assessment, only one model 
has been designed so far which allows for a true scientific approach to studying the structure of stratification dimensions. The model was constructed by Saksida and later served as a basis for many studies conducted by other authors as well (Saksida, Caserman and Petrovic, Momirovic and Hosek). Developed as a phenomenological model, it has undergone several changes over time but it still remains suitable for studying social change. INST2 and SSMIN questionnaire modified by Boli, D. Popovic, Hosek-Momirovic, J. Popovic, and Savic (2012) were applied in this research.

All the data obtained in this study were processed at the Multidisciplinary Research Center of the Faculty of Sport and Physical Education, University of Pristina, through the system of data processing programs developed by Popovic (1980; 1993a; 1993b) and Momirović and Popović (2003).

To determine differences between the groups, a method of discriminant analysis was applied.

The results of the discriminant analysis in the space of social status are shown in Tables 1-4. Analyzing them, it can be determined that a significant canonical correlation of .97 which explains $100.0 \%$ of the valid variance of the whole system of the evaluated space was obtained.

This discriminant function is defined by the achieved sport results (SPORTAC), type of school (SCHOOL), sport in which father was engaged (SPORTFA), size of living space (APARTM), sport in which the respondent is engaged (SPORT), household income (INCOME), type of place where the respondent lived as a child until 15 years of age (P15), type of place where father lived as a child until 15 years of age (P15FA), type of place where mother lived as a child until 15 years of age (P15MO), mother's professional qualification (QUALMO), maternal grandfather's education (EDUMAGRFA), mother's foreign language knowledge (FOLMO).

Based on the values and signs of the centroids for the first discriminant function of the groups, it can be concluded that male dancers have a better educational status - the individual's level of education, mother's status in the society within the socialization subsystem, professional status expressed by the degree of mother's expert power in her working organization, and better achievements in sport. Femal dancers have a better language-knowledge status and a better economic status quantified by the variables (APARTM and INCOME), as well as the residential status quantified by the variable (PLACE) and basic residential status - characteristics of the place where the subject spent his or her childhood, and partially educational status (EDUMAGRFA). Comparing the discriminant analysis results to the regression analysis data shows that success in dancing is influenced by the variables (SCHOOL), where male dancers are better, APARTM and INCOME, where female dancers are better, and FOLMO, mother's knowledge of foreign languages, where female dancers are better.

\section{References}

Anderson, T. W. 1984. An Introduction to Multivariate Statistical Analysis. 2nd ed. New York: Wiley.

Boli, E. 2011. The Structure of Anthropological Dimensions of Male and Female Dancers and Development of Methods for Their Assessment and Monitiring. Monograph. Multidisciplinary Research Center, Faculty of Sport and Physical Education, University of Pristina, Leposavic.

Boli, E., D. Popovic, A. Hosek-Momirovic, J. Popovic, and V. Savic. 2012. "The Social Status Structure of Dancers." International Scientific Journal Kinesmetrics 1(1):179.

Boli, E., D. Popovic, and J. Popovic. 2012. "Differences in the Level of Musical Abilities of Male and Female Dancers." International Scientific Journal Kinesmetrics 1:67-89.

Boli, E., V. Stankovic, D. Popovic, K. Taxildaris, and M. Bojovic. 2013. "Discriminant Analysis in Space With Standard Metric." International Scientific Journal Kinesmetrics 2(1):55.

Bucal, A. 2012. "Influence of Socioeconomic Status of Students on Their Academic Achievement: Direct and Indirect Influence." Primenjena psihologija (Applied Psychology) 5(1):5-24

Čikić, J. 2014. "Change in the Educational Structure in the Postsocialist Transition Serbian Experience." Nis: "The Themes" 38(3):1037-1056. 
Guttman, L. 1945. "Basis for Test-Retest Reliability Analysis." Psychometrika 10:255-282.

Kendall, M. G. and A. Stuart. 1968. The Advanced Theory of Statistics. Vol. 3. London: Griffin.

Momirovic, D., B. Wolf, and D. Popovic. 1999. Introduction to the Theory of Measurement and Internal Metric Properties of Composite Measurement Instruments. Textbook. Faculty of Physical Education, University of Pristina, Pristina.

Momirovic, K. 1999. Two Measures of Low and High Reliability of Tests With Regulatory and Singular Matrix of Particles Covariance. Technical Report, Institute of Criminological and Sociological Research, Gracanicka 18, Belgrade.

Momirovic, K. and D. Popovic. 2003. Construction and Application of Taxonomic Neural Networks. Multidisciplinary Research Center, Faculty of Physical Education, University of Pristina, Leposavic.

Popovic, D. 1980. "Research Methodology in Physical Education." Textbook, University of Nis, "Scientific Youth", Nis.

—. 1988. "Application of Factor Analysis Methods for Determining Morphological Types." Presented at the 4th International Symposium on the Methodology of Mathematical Modelling. Varna, Bulgaria.

—. 1990. "Research Methodology in Physical Education." Textbook, University of Nis, "Scientific Youth", Nis.

- 1992. Research Methodology in Physical Education. Athens, Greece: Petar Novakovic.

- 1993a. Determination of the Structure of Psychosomatic Dimensions in Combats and Development of Methods for Their Assessment and Monitoring. Monograph. Faculty of Physical Education, University of Pristina, Pristina.

- 1993b. Programs and Subprograms for the Analysis of Quantitative Modifications. Textbook. Multidisciplinary Research Center, Faculty of Physical Education, University of Pristina, Pristina.

- 2005. "GUTTMAN, Programs for Analysis of Metric Characteristics of Composite Measurement Instruments." In Influence of Situational Training on Transformation of Some Anthropological Dimensions in Selected Footballers (doctoral thesis), edited by Z. Savić. Faculty of Physical
Education, Leposavic.

Popovic, D., E. Boli, E. Shagal, and V. Savic. 2013. "Influence of Cognitive Abilities, Conative Characteristics and Social Status of Students on Their School Grades in Mother Tongue." International Scientific Journal Kinesmetrics 2(1):5.

Popovic, D., J. Kocic, E. Boli, and V. Stankovic. 1995. "Conative Characteristics of Female Dancers." Presented at the International Congress "Images of Sport in the World". P. 96 in 75th Anniversary of the German Sport University, Abstract Volume. Cologne, Germany.

Popovic, D., J. Petrovic, E. Boli, and V. Stankovic. 1995. "The Personality Structure of Female Dancers." Presented at the 3rd International Congress on Physical Education and Sport. Komotini, Greece. Exercise \& Society Supplement Issue 11:196.

Popovic, D., K. Antic, V. Stankovic, V. Petkovic, and S. Stankovic. 1989. "The Procedures for Objectification of Estimating the Effectiveness of Performing Judo Techniques." Scientific Youth 21(1-2):83-89.

Popovic, D., V. Stankovic, R. Kulic, and P. Grigoropulos. 1996. "The Personality Structure of Handball Players." Presented at the 4th International Congress on Physical Education and Sport. Komotini, Greece. Exercise \& Society Supplement Issue 15:164.

\section{Bios}

Evagelia Boli, Ph.D., professor, Faculty of Sport and Physical Education, University of Pristina; research fields: sociology and dance.

Dragan Popović, Ph.D., professor, Faculty of Sport and Physical Education, University of Pristina; research fields: computational statistics, computer programming, mathematical psychology, kinesiology, and motor control.

Biljana Karanov, assistant, Sports Academy, Belgrade; research field: dance.

Milica Bojević, assistant, Faculty of Sport and Physical Education, University of Pristina; research field: dance.

Marina Jovanović, assistant, University of Pristina; research field: dance. 